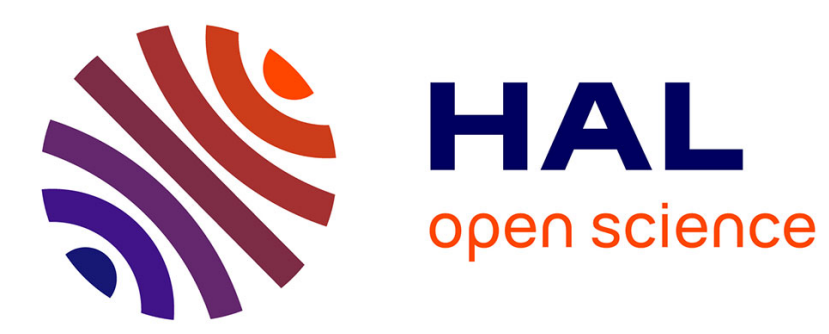

\title{
Design of a dilution refrigerator and sample holder operating in pulsed field
}

P Pari, P Forget, Ph Hernandez, F Ladieu, M. Sanquer, I.M. Broto, H Rakoto, G Coffe, S M Askenazy

\section{> To cite this version:}

P Pari, P Forget, Ph Hernandez, F Ladieu, M. Sanquer, et al.. Design of a dilution refrigerator and sample holder operating in pulsed field. Physica B: Condensed Matter, 1995, 211, pp.366 - 368. 10.1016/0921-4526(94)01064-8 . cea-01396504

\section{HAL Id: cea-01396504 https://hal-cea.archives-ouvertes.fr/cea-01396504}

Submitted on 14 Nov 2016

HAL is a multi-disciplinary open access archive for the deposit and dissemination of scientific research documents, whether they are published or not. The documents may come from teaching and research institutions in France or abroad, or from public or private research centers.
L'archive ouverte pluridisciplinaire HAL, est destinée au dépôt et à la diffusion de documents scientifiques de niveau recherche, publiés ou non, émanant des établissements d'enseignement et de recherche français ou étrangers, des laboratoires publics ou privés. 


\title{
Design of a dilution refrigerator and sample holder operating in pulsed field
}

\author{
P. Pari ${ }^{\mathrm{a}}$, P. Forget ${ }^{\mathrm{a}}$, Ph. Hernandez ${ }^{\mathrm{a}}$, F. Ladieu ${ }^{\mathrm{a}}$, M. Sanquer ${ }^{\mathrm{a}}$, I.M. Broto ${ }^{\mathrm{b}, *}$, H. Rakoto ${ }^{\mathrm{b}}$, \\ G. Coffe ${ }^{\mathrm{b}}$, S. Askenazy \\ a Centre d'Études de Saclay, Service de Physique de l'Etat Condensé, 91191 Gif-sur-Yvette, France \\ ${ }^{\mathrm{b}}$ Service National des Champs Magnétiques Pulsés, I.N.S.A., Complexe Scientifique de Rangueil, F-31077 Toulouse cedex, France
}

\begin{abstract}
We have constructed a compact dilution refrigerator which can lower the temperature from $300 \mathrm{~K}$ to $50 \mathrm{mK}$ in less than $3 \mathrm{~h}$, and operate in a pulsed magnetic field. To avoid eddy currents due to contacts with the sample we design an original sample holder.
\end{abstract}

We describe how to measure magnetoresistance in pulsed magnetic field up to $36 \mathrm{~T}$ at $T=60 \mathrm{mK}$ without significant heating of the sample.

To avoid large eddy currents, the metallic parts of the refrigerator (4 K flange, Joule-Thomson exchanger, metallic parts of the composite boiler and heat exchangers) are mainly situated outside the magnet. But, even with the use of a complete plastic lower part (mixing chamber and its connections), metallic wires to the sample are possible sources of heating in large varying flux. It is important to avoid the diffusion of this heat to the sample during the measurement time of approximately $1 \mathrm{~s}$. For this purpose, we design a composite sample holder which includes a quartz radiator (dissipating the heat coming from the upper wires in short times) in series with highly resistive electrical contacts down to the sample (in order to reduce the diffusion of residual heat). To test the whole system, we measure the magnetoresistance of a sample exhibiting a large temperature dependence of its resistance. We compare the results in pulsed field with that in a continuous $8 \mathrm{~T}$ field and obtain that

* Corresponding author. the sample temperature is increased from 60 to $70 \mathrm{mK}$ during the pulse.

The characteristics of the pulsed field are detailed in Ref. [1]: the field is obtained by discharge of a capacitor bank storing $1.25 \mathrm{MJ}$ at $10 \mathrm{kV}$. The coil produces $42 \mathrm{~T}$ in an inner diameter of $15 \mathrm{~mm}$ at $T=4.2 \mathrm{~K}$. The field first increases to its maximum value in $0.1 \mathrm{~s}$, and then decreases in $1 \mathrm{~s}$. During this decrease, we measure the voltage across the sample either with $\mathrm{DC}$ or $\mathrm{AC}$ fixed injected current and 4-probe technique.

We use a dilution refrigerator without separated condensation stage, because of its compactness and its easyto-use qualities. The cooling time from room temperature to $T=50 \mathrm{mK}$ is only $3 \mathrm{~h}$. The cooling power at $T=100 \mathrm{mK}$ is $20 \mu \mathrm{W}$.

Due to the small available diameter, we cannot build a plastic heat exchanger near the mixing chamber, but we construct composite fiberglass-epoxy resin tubes (diameter $1 \mathrm{~mm}$ ) to connect the mixing chamber to the metallic heat exchanger located out of the coil where the residual field is only $1 / 100$ the nominal value (see Fig. 1).

The mixing chamber itself is from epoxy resin and sample and thermometer are placed inside the helium mixture (Fig. 2). Typically the maximum variation of flux 


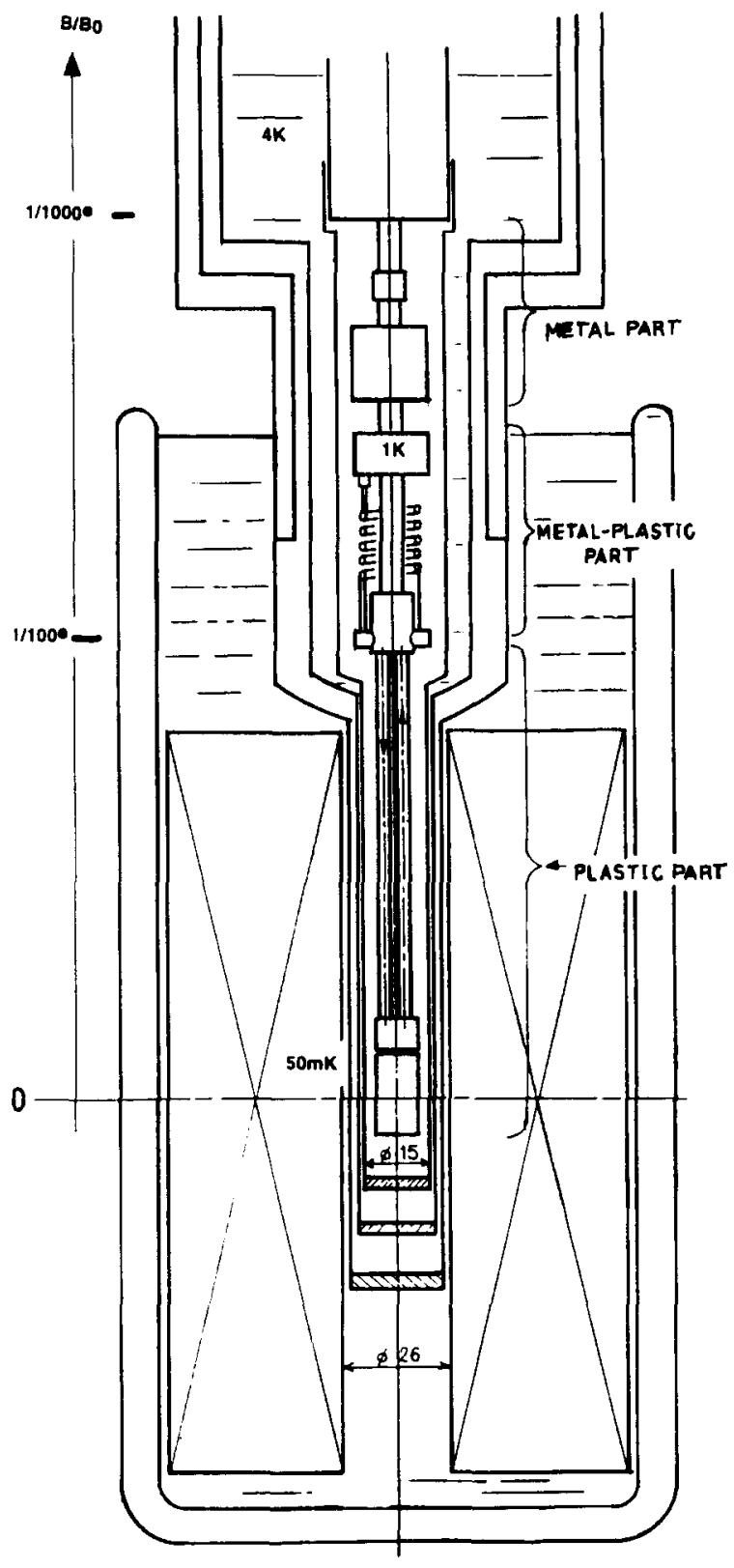

Fig. 1. Lower part of dilution refrigerator in the coil.

dissipates an energy of about $1 \mu \mathrm{J}$ for four Au-wires of $25 \mu \mathrm{m}$ diameter and $10 \mathrm{~mm}$ long. Since the energy $E$ varies as $1 / \rho$, to minimize this dissipation, one uses thin films of high resistivity $\rho$ and small cross-section. But high resistivity means large specific heat $C$ at very low temperature. The time constant $\tau$ of thermal coupling with the helium bath is given by $\tau=R C$ where the contact resistance $R$ varies as $T^{-3}$. Typical estimation of

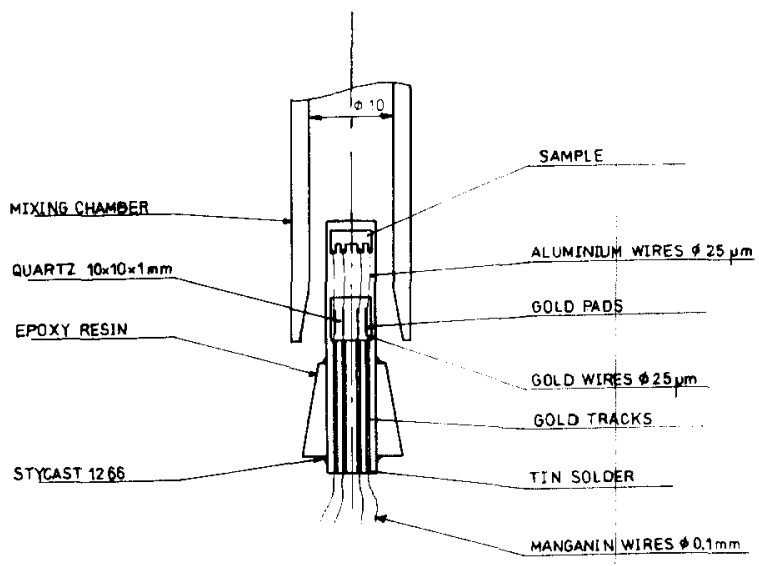

Fig. 2. Sample holder and mixing chamber.

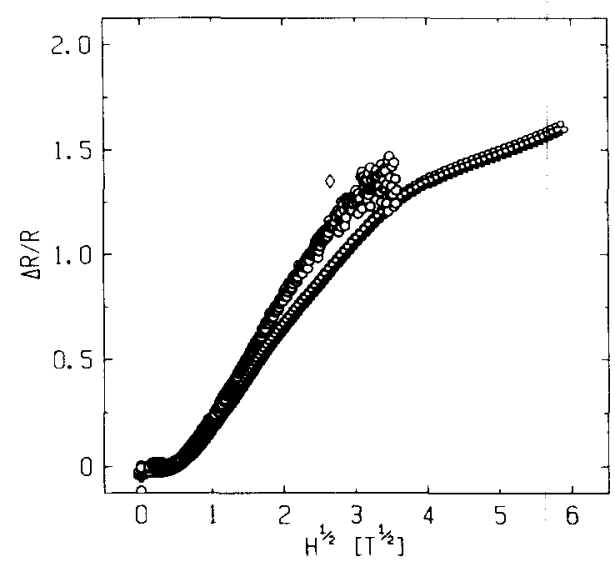

Fig. 3. $\Delta R / R=[R(H)-R(0)] / R(0)$ versus $H^{1 / 2}$ at $T=60 \mathrm{mK}$ in constant field of $7 \mathrm{~T}(\diamond)$, and for 2 pulsed field experiments.

$\tau$ at $T=50 \mathrm{mK}$ for a constantan wire $(25 \mu \mathrm{m}$ diameter, $10 \mathrm{~mm}$ long) is $1 \mathrm{~s}$. This large time constant implies a large heating of standard wires and consequently of the sample during the experiment. In order to avoid the heating of the sample, we put a radiator between the high resistive films and the sample. It consists of quartz crystal of $10 \mathrm{~mm} \times 10 \mathrm{~mm}$ surface and $0.1 \mathrm{~mm}$ thickness with four sputtered Au pads. Then we contact the sample with $\mathrm{Al}$ or $\mathrm{Au}$ wires $(\varnothing=25 \mu \mathrm{m})$ by ultrasonic soldering. Due to the low heat capacity of the quartz, the heat coming to the pads diffuses very rapidly in the quartz (large diffusivity), and then is dissipated in a short time (small time constant of thermal coupling to the bath). Moreover, because the quartz itself has a large contact area with the helium bath, a large volume of the liquid is involved in dissipation during a small time; this is 
necessary to maintain the quartz at low temperature. We have calculated an increase of $5 \mathrm{mK}$ at $60 \mathrm{mK}$ for $1 \mu \mathrm{J}$ of dissipated energy by eddy current in the metallic part of the sample holder into the mixture inside the mixing chamber. In addition, there is energy dissipated in the metallic parts of diffusion stage outside the coil, and the associated heating of the helium bath diffuses only after $10 \mathrm{~s}$ into the mixing chamber due to the flow rate of the concentrated phase.

To test the dilution refrigerator in the coil, we have measured both a $\mathrm{RuO}_{2}$ calibrated sensor $(1.58 \mathrm{k} \Omega$ Dale resistor) and our sample. The sample itself is a very good thermometer due to the large temperature dependence of its resistance. The fit at $H=0$ is given by $R=27.71$ $\exp (3.145 / T)^{1 / 4}$. It consists of an amorphous $\mathrm{Y}_{0.2} \mathrm{Si}_{0.8}$ alloy which is in the variable Range Hopping Mott regime below $T=1 \mathrm{~K}$ [2]. In addition it presents a very large positive magnetoresistance, such that one discriminate between heating, which produces.a negative variation of the resistance, and magnetoeffect. First we measure the magnetoresistance in constant magnetic field of 0 and $7 \mathrm{~T}$ at $60 \mathrm{mK}$ : with the field the resistance increases from 400 to $947 \Omega$. This magnetoresistance is reported on Fig. $3(\diamond)$.

Then we measure the whole magnetoresistance curve in a pulsed magnetic field at the same temperature (i.e. we choose the same $H=0$ sample resistance). We observe coincidence to well within $10 \mathrm{mK}$ of the measured values of $\Delta R(H)$ at $H=7 \mathrm{~T}$. In addition, we make another pulsed field experiment with the variation of flux increased by a factor 3 , and confirm that the measured magnetoresistance depends only smoothly on this factor. To conclude, the value of $R(7 \mathrm{~T})$ obtained with the faster field sweep is the same as obtained in DC field at $7 \mathrm{~T}$ and $70 \mathrm{mK}(830 \Omega$ measured).

\section{References}

[1] S. Askenazy, J. Marquez and D. Ricard, Physica B 155 (1989) 55

[2] P. Hernandez and M. Sanquer, Phys. Rev. Lett. 68 (1992) 1402. 